Revista de

Contabilidade e

Organizações

www.rco.usp.br
DOI: http://dx.doi.org/10.11606/issn.1982-6486.rco.2018.138529
Journal of

Accounting and

Organizations

www.rco.usp.br

\title{
Recomendações aos comitês de auditoria em empresas brasileiras
}

\section{Recommendations for audit committees in Brazilian companies}

Alini da Silva ${ }^{\text {a }}$; Paulo Roberto da Cunha ${ }^{\text {a; }}$ Silvio Aparecido Teixeira ${ }^{a}$

${ }^{a}$ Universidade Regional de Blumenau

\section{Palavras-chave}

Características do Comitê de auditoria.

Deficiências de Controle Interno.

Empresas Brasileiras.
Keywords

The Audit Committee characteristics.

Internal control deficiencies.

Brazilian companies.

\section{Resumo}

O presente estudo analisa a relação entre as características do comitê de auditoria e as deficiências do controle interno em empresas brasileiras. A amostra do estudo envolveu cerca de 80 empresas que possuíam comitês de auditoria, no período de 2010 a 2015. Foram utilizadas a análise de entropia da informação, a estatística descritiva e a regressão linear múltipla. Os resultados demonstraram que empresas que possuem no mínimo três membros no comitê de auditoria, em relação àquelas que possuem menos que três membros, apresentaram menores deficiências no controle interno. Este resultado fortalece a prerrogativa de organismos regulatórios de ser adotado um mínimo de três membros para o comitê de auditoria para empresas brasileiras, contribuindo para a diminuição das deficiências do controle interno.
Informações do Artigo

Recebido: 27 de setembro de 2017

Aceito: 18 de julho de 2018

Publicado: 24 de julho de 2018

\begin{abstract}
The study analyzes the relationship between the characteristics of the audit committee and the deficiencies of internal control in Brazilian companies. The study sample comprised about 80 companies that adopted audit committee in the period from 2010 to 2015. We applied information entropy analysis, descriptive statistics and multiple linear regression. The results showed that companies that have at least three members in the audit committee, in relation to those with less than three members, have significantly reduced internal control deficiencies. This result strengthens the prerogative of regulatory bodies to adopt a minimum of three members for the audit committee for Brazilian companies, contributing to the reduction of deficiencies in internal control.
\end{abstract}

\section{Implicações práticas}

Os comitês de auditoria, mandatórios para alguns segmentos no Brasil, adotados por empresas listadas são compostos por uma proporção maior de membros com baixa expertise. Nos quase 80 casos analisados, comitês com o mínimo recomendado de três membros tendem a ter menos ocorrências de deficiências de controle identificadas, apesar da baixa expertise dos membros.

Copyright (C) 2018 FEA-RP/USP. Todos os direitos reservados

\section{INTRODUÇÃO}

A governança corporativa e seus mecanismos de controle têm por intuito garantir a conformidade dos procedimentos da empresa com os princípios de contabilidade, conferindo credibilidade sobre as demonstrações financeiras da empresa. Esta auxilia também na atenuação de comportamentos oportunistas dentro da empresa, pela criação e gestão de comitês, em que se destaca o de auditoria (Inaam \& Khamoussi, 2016). Em 1940, a Securities and Exchange Commission - SEC dos EUA, as empresas de auditoria e algumas organizações começaram a recomendar a criação do comitê de auditoria em empresas.

Autor Correspondente: Tel. (47) 3321-0200

E-mail:alinicont@gmail.com (A. Silva); pauloccsa@furb.br (P. R. Cunha); silvioteixeira@sercomtel.com.br (S. A. Teixeira)

FURB - Universidade Regional de Blumenau. R. Antônio da Veiga, 140 - Victor Konder, Blumenau - SC, 89030-903, Brasil 
De acordo com tais organismos, a implantação de um comitê de auditoria auxilia a independência e efetividade da empresa, considerado como um importante mecanismo de governança corporativa para auxiliar na transparência de informações. No mercado brasileiro, a Comissão de Valores Mobiliários (CVM) apesar de incentivar as companhias, principalmente, não financeiras a implantar comitês de auditoria, não as obriga. Os comitês são obrigatórios desde 2004 para instituições financeiras e seguradoras ${ }^{1}$.

Organismos como o Novo Mercado da B3 e o Instituto Brasileiro de Governança Corporativa (IBGC) têm recomendado a adoção dos comitês de auditoria. Porém, não se observa obrigação de implantação do comitê de auditoria a todas as empresas, apenas a grupos específicos regidos por instruções como Novo Mercado, Estatais, Financeiras (IBGC, 2017). Assim, de acordo com Peleias, Segreti e Costa (2009) as demais empresas não regidas por instruções específicas podem adotar voluntariamente o comitê de auditoria, ou apenas melhorar as funções do comitê fiscal.

O comitê de auditoria, juntamente com o conselho de administração, possui como uma de suas atribuições o monitoramento dos controles internos das empresas para que operem com efetividade e não demonstrem deficiências (Krishnan, 2005). Entretanto, por mais que haja o comitê de auditoria implantado nas empresas, somente a sua adoção não garante a eficácia de suas funções, ou seja, as empresas podem continuar a enfrentar problemas nos seus controles internos, prejudicando potencialmente a fidedignidade das demonstrações contábeis.

A redução de problemas de controles internos nas empresas depende da existência de um comitê com características específicas (independência, tamanho, expertise). Estudos empíricos apontam como características do comitê de auditoria, que favorecem a redução de problemas de controle em empresas americanas, o tamanho do comitê (Krishnan, 2005; Goh, 2009), a experiência financeira (Krishnan, 2005; Zhang, Zhou \& Zhou, 2007; Goh, 2009), a independência (Krishnan, 2005; Goh, 2009) e a escolaridade dos membros (Lin, Pizzini, Vargus \& Bardhan, 2011). O comitê de empresas americanas, ainda deve atender às exigências da SEC de divulgar informações sobre o controle interno de acordo com as seções 302, 404 e a Lei SOX - Sarbanes Oxley (Hogan \& Wilkins, 2008).

Com essa nova normatização, vários estudos investigaram os efeitos da SOX no controle interno, com uma predominância de estudos que avaliaram a questão de deficiências de controle interno (Ge \& Mcvay, 2005; Doyle, Ge \& Mcvay, 2007; Zhang et al. 2007; Goh, 2009; Kim \& Park, 2009; Bedard \& Graham, 2011; Lin et al. 2011; Teixeira, 2015). Contudo, tais pesquisas não são comuns para o cenário brasileiro. Por exemplo, ainda não foram investigadas quais características do comitê de auditoria que podem inibir as deficiências de controle.

Considerando o aspecto de formação voluntária de tais comitês para o mercado brasileiro, este estudo analisa a relação entre as características do comitê de auditoria existentes e as deficiências do controle interno pelas empresas que optaram por ter tais comitês.

Analis ou-se uma amostra de 73 empresas listadas no mercado brasileiro no período de 2010 a 2015, que possuem comitì de auditoria. As deficiências de controle interno foram identificadas por análise de conteúdo nos relatórios das: empresas, seguindo o método empregado em Teixeira (2015).

Os resultados apontaram que empresas, as quais possuem no mínimo três membros no comitê de auditoria apresentaranı redução das deficiências de controle interno. Este achado demonstra a importância da adoção da prerrogativa de organismos como NYSE, NASDAK, SEC, IBGC de se ter no mínimo três membros no comitê de auditoria, no cenário de empresas brasileiras, visto que, além de reportar eficiência no comitê, contribui para a diminuição das deficiências do controle interno.

Apesar de algumas informações sobre as características do comitê de auditoria geralmente não se encontrarem disponíveis para usuários externos (Krishnan, 2005), o comitê de auditoria reduziria as deficiências de controle (Stefaniak, Houston \& Cornell, 2012). A ausência de um controle interno pode suscitar atos fraudulentos, negligência, distração ou falhas nos processos organizacionais (Teixeira, 2015). Alguns exemplos icônicos podem ser dados. A Enron Corporation, uma das principais empresas no ramo de energia no mundo, foi prejudicada por fraudes, provavelmente associadas com falhas em controles, contribuindo para a descontinuidade dos negócios.

\footnotetext{
${ }^{1}$ O Comitê de Auditoria Estatutário é detalhado na Instrução CVM n. 509 de 2011, sendo obrigatório apenas para instituições financeiras e seguradoras desde 2004 (IBGC, 2017).
} 


\section{COMITÊ DE AUDITORIA E CONTROLE INTERNO}

A governança corporativa possui um conjunto de mecanismos e práticas, que visam à harmonização das relações entre usuários da informação contábil, bem como o desenvolvimento da empresa. É requerido que a administração da empresa defina os órgãos responsáveis por dirigir e monitorar as ações organizacionais, e as responsabilidades de cada órgão. Tais órgãos correspondem principalmente ao conselho de administração e auditores independentes.

O conselho de administração delega tarefas para executivos administrarem a empresa, e para comitês específicos, os quais devem supervisionar determinadas áreas da empresa (Peleias et al., 2009). Apesar da responsabilidade de estabelecer e manter o controle interno de forma adequada, na visão da SEC, ser do conselho de administração, este delega tal função ao comitê de auditoria (Krishnan, 2005). O comitê de auditoria é formado por membros do conselho de administração, sendo responsável pela supervisão dos processos organizacionais e divulgação de informações financeiras ao mercado de capitais (Peleias et al., 2009).

Este comitê analisa a integridade dos controles internos, atua como meio de comunicação entre a auditoria externa e a empresa, e procura garantir os interesses dos usuários da informação contábil. Ainda, tem como responsabilidade a supervisão do processo e divulgação de informações financeiras da empresa (Klein, 2002). Para isso o comitê deve se reunir regularmente com auditores externos e administradores da empresa, reportando informações, revendo demonstrações financeiras, processos de auditoria, bem como controles internos da empresa.

O comitê de auditoria, praticamente, não existia até a publicação da SOX nos Estados Unidos. Após a publicação desta lei, o comitê ganhou destaque e é considerado um importante mecanismo, por atuar na gestão de riscos da empresa, monitorar os processos organizacionais e intermediar o contato de empresa, auditores independentes e demais usuários da informação contábil (Silva, Oliveira, Mendes \& Araújo, 2009). Tornou-se um importante elemento da governança corporativa para a SEC, e imprescindível para assegurar a qualidade da informação contábil divulgada para o mercado de capitais (Goh, 2009).

Por outro lado, os controles internos, monitorados pelo comitê de auditoria, podem possuir deficiências, os quais podem prejudicar os procedimentos organizacionais. De acordo com Zhang et al. (2007), os problemas de controle interno são classificados de acordo com sua gravidade como, por exemplo, fraqueza material, deficiência significativa e deficiência de controle interno.

Primeiro, fraqueza material associa-se com deficiências significativas que ocorrem na empresa, e que impedem com grande probabilidade o reconhecimento de uma distorção relevante nas demonstrações financeiras (Doyle et al., 2007; Lin et al., 2011). Já a deficiência significativa ou combinação de deficiências de controle, prejudica o processamento e divulgação de informações financeiras de acordo com princípios e normas de contabilidade. Por fim, a deficiência de controle interno ocorre quando agentes da empresa, por meio dos controles, não conseguem prevenir ou detectar distorções em tempo hábil (Zhang et al., 2007).

No contexto brasileiro, a Norma de Auditoria NBCTA 265 item 6, argumenta que existe deficiência de controle interno, quando "o controle é planejado, implementado ou operado de tal forma que não consegue prevenir, ou detectar e corrigir tempestivamente, distorções nas demonstrações contábeis" ou quando há falta de um controle que previne, detecte ou corrige distorções (NBCTA 265, item 6). A norma ainda apresenta que "a deficiência significativa ou a combinação de deficiências de controle interno, é de importância suficiente para merecer a atenção dos responsáveis pela governança", segundo o julgamento profissional do auditor (NBCTA 265, item 6).

As deficiências de controle interno em geral são associadas a recursos inadequados aplicados à função contábil, tais como: falta de pessoal qualificado em contabilidade; políticas deficientes sobre o reconhecimento de receitas; falta de segregação de funções; inadequadas conciliações de contas contábeis; deficiências de controle em subsidiárias (caso a empresa possua) e problemas de controle em contas complexas - instrumentos financeiros, derivativos, imposto de renda - (Ge \& Mcvay, 2005).

A legislação norte-americana, por meio da SOX, exige que as empresas divulguem informações sobre o controle interno por meio de relatórios, certificando que os processos e procedimentos de controle são aplicados de acordo com a seção 302 da referida lei. Ainda, por meio da seção 404, a SOX exige que as empresas divulguem um relatório sobre a eficácia dos controles internos da empresa e que a auditoria externa audite e avalie esta eficácia do controle (Hogan \& Wilkins, 2008). Como não há exigência de atendimento à SOX ou similar para empresas listadas apenas no mercado brasileiro, as informações a respeito das deficiências do controle interno acabam por serem restritas. Fato que pode reduzir a realização de estudos empíricos nesta temática. Contudo, o construto de deficiências de controle interno, desenvolvido por Teixeira (2015), permite identificar diversas dimensões de deficiências do controle interno em empresas brasileiras, por meio da análise dos relatórios dessas empresas. 
O autor realizou uma vasta pesquisa com análise de conteúdo das normas NBCTA 265, NBCTA 315, assim como Ge e Mcvay (2005), que identificaram alguns tipos de deficiências, propondo como identificá-las nos relatórios dessas empresas. As dimensões de deficiências de controle interno propostas em Teixeira (2015) são as seguintes: deficiência em conta contábil específica, deficiência na elaboração de demonstrações contábeis, deficiências em subsidiárias, deficiências de tecnologia, deficiências da alta administração, deficiências de litígios e deficiências gerais.

A deficiência de controle interno em conta específica relaciona-se com deficiências ocasionadas nas operações com regulamentação complexa, transações não usuais e internacionais, incerteza de mensuração de contas e de contas complexas. As deficiências com demonstrações contábeis referem-se a problemas com o não registro de instrumentos financeiros, com os funcionários da área contábil, normas contábeis, distorções passadas e futuras. Em relação às deficiências com subsidiárias entendem-se como problemas com controle compartilhado, aquisições, reorganizações e transações entre as partes (Teixeira, 2015).

Ainda, deficiências de tecnologia referem-se à incompatibilidade entre TI - tecnologia da informação e negócios, mudanças de sistemas e a utilização de novos sistemas. Deficiências com a alta administração relacionam-se com operações instáveis, problemas com a continuidade da empresa, mudanças de atividades e produtos, mudança de localização e da administração. As deficiências com litígios configuram-se em problemas com órgãos reguladores e obrigações contingentes. E, por fim, deficiência geral relaciona-se com problemas no monitoramento da empresa, revisão ou implantação de novo controle, problemas com segregação de funções, conciliação de contas, erros ou fraudes (Teixeira, 2015). De acordo com o autor a classificação das deficiências em dimensões auxilia na análise da natureza de cada problema.

\subsection{Relação entre as características do comitê de auditoria e as deficiências de controle interno}

O comitê de auditoria possui determinadas características associadas com a qualidade, tais como ter membros com experiência em finanças, contabilidade ou auditoria (Carcello \& Neal, 2003; Goodwin-Stewart \& Kent, 2006), ter membros independentes da empresa (Abbott, Parker \& Peters, 2004), além de reuniões frequentes tratando do desempenho da empresa e suas funções, com o intuito de desenhar melhorias (Goodwin-Stewart \& Kent, 2006; Barua, Rama, \& Sharma, 2010).

Infere-se, que as características do comitê de auditoria estão relacionadas com a qualidade dos controles internos das empresas. O efeito do comitê se dá em maior supervisão destes, na revisão dos procedimentos contábeis e na discussão com os auditores para corrigir as deficiências. Ainda, o comitê de auditoria induz a administração da empresa a investir recursos na correção dos problemas de controle (Goh, 2009).

Em Krishnan (2005) a qualidade do comitê de auditoria (tamanho, experiência e independência) reduz problemas de controle interno (condições reportáveis e fraquezas materiais) de empresas. Esse efeito decorre da maior independência e experiência financeira, capazes de reduzir a incidência de problemas de controle.

$\mathrm{O}$ efeito da qualidade do comitê de auditoria, da independência do auditor e da divulgação de deficiências de controle interno, após a promulgação da SOX também foi investigado por Zhang et al. (2007). Para empresas segregadas em duas amostras (com e sem deficiência de controle interno) os autores constataram que as empresas estão mais propensas a ter deficiência quando o comitê de auditoria possui pouca experiência financeira, quando os auditores externos são mais independentes e quando há mudança de auditoria recente. A especialização do comitê também aparece no estudo de Goh (2009), em que empresas com comitê de auditoria maior, com maior experiência financeira e independência são mais propensas a corrigir as deficiências de controle interno em tempo hábil.

Especificamente sobre o tamanho do comitê de auditoria, Goh (2009) sugeriu que as empresas podem melhorar o monitoramento dos controles internos, expandindo seus comitês de auditoria, com a contratação de mais membros, embora a exigência das principais bolsas dos EUA seja de comitês de auditoria formados por pelo menos três diretores. A SEC e demais organismos normativamente recomendam a formação do comitê de auditoria com no mínimo três membros.

Em 1999 e 2003, a SEC aprovou requisitos de composição e estrutura do comitê de auditoria, introduzidas pelas principais bolsas como NYSE e NASDAK. Assim, todas as empresas deveriam ter seus comitês de auditoria constituídos por pelo menos três membros, além de exigir características de independência e expertise para estes (SEC, 2003; Krishnan, 2005). 
Krishnan (2005) analisou a composição dos comitês de auditoria em empresas americanas, considerando o tamanho mínimo de três membros, a independência e a expertise como proxys para a qualidade do comitê. $\mathrm{O}$ autor constatou que a maior propensão é empresas com comitês formados por três ou mais membros, e uma maior proporção de membros independentes e com expertise.

Nacionalmente, CVM, Banco Central do Brasil e B3 também recomendam a prerrogativa de o comitê de auditoria com no mínimo três membros, sendo a adoção para alguns setores e mercados obrigatória. A CVM normatiza pela instrução $n^{0} 509 / 11$, Estatais pela Lei $n^{\circ} 13.303$, o Banco Central do Brasil com a Resolução $n^{\circ}$ 3.198 e a B3 pela regulação do Novo Mercado. A recomendação emitida por estes organismos difere na composição desses 3 membros, variando na demanda por independência e expertise (IBGC, 2017).

De acordo com o IBGC (2017) o tamanho mínimo recomendado ao comitê de auditoria varia com o porte da organização ou complexidade dos negócios. Contudo, recomenda-se de maneira geral o mínimo de três membros. No caso de mais membros, deve-se adotar um número ímpar de membros. Para o IBGC tal composição facilita a diversidade no comitê, promovendo visões diferenciadas de mundo dos profissionais com diferentes perfis e experiências. A diversidade no comitê de auditoria, segundo o IBGC (2017), incentiva a pluralidade de comunicação e argumentos, gerando um processo de decisão de maior qualidade e segurança, em que idealmente todos os membros tenham conhecimento na área de negócios para auxiliar neste processo.

Somada as características do comitê de auditoria, que concedem maior qualidade de atuação e também podem auxiliar na minimização de problemas de controle, Lin et al. (2011) identificaram que a escolaridade de membros da auditoria interna influencia significativamente na divulgação de deficiências de controle interno e fraquezas materiais relatados de acordo com a seção 404 da SOX.

Assim, as características do comitê de auditoria, principalmente o tamanho do comitê, a experiência financeira e a independência dos auditores internos (Krishnan, 2005; Goh, 2009) estão associados com a redução dos problemas de controle interno (Krishnan, 2005; Zhang et al., 2007; Goh, 2009; Lin et al., 2011).

Desta forma, com o intuito de avaliar estes pressupostos no cenário de empresas brasileiras, delimitaramse as seguintes hipóteses de pesquisa.

$\mathbf{H}_{1}$ : O tamanho do comitê de auditoria é negativamente associado com as deficiências de controle interno.

$\mathbf{H}_{2}$ : O mínimo de três membros no comitê de auditoria está negativamente associado com as deficiências de controle interno.

$\mathbf{H}_{3}$ : A experiência financeira do comitê de auditoria está negativamente associada com as deficiências de controle interno.

$\mathbf{H}_{4}$ : A independência do comitê de auditoria está negativamente associada com as deficiências de controle interno.

\section{PROCEDIMENTOS METODOLÓGICOS}

O objetivo é analisar a relação entre as características do comitê de auditoria e as deficiências do controle interno em empresas brasileiras. A seleção da amostra da pesquisa partiu da população das empresas listadas na $\mathrm{B}^{2}$. Ao final, a amostra foi composta por 71 a 80 empresas listadas na bolsa que possuíam comitê de auditoria em cada ano analisado (71 em 2010, 71 em 2011 a 2013, 75 em 2014 e 80 em 2015).

Para estas empresas, as informações válidas em todas as variáveis analisadas estavam disponíveis em todo o período analisado. O período de análise (2010 a 2015) reuniu 439 observações. Os dados não são balanceados, ou seja, não são as mesmas empresas em todos os anos, utilizou-se desta abordagem a fim de se ter maior quantidade de observações. Adotamos a metodologia de Teixeira (2015) para a identificação das deficiências de controle interno nas empresas brasileiras analisadas. A análise de conteúdo nos relatórios das empresas foi organizada nos sete grupos de deficiências de controle interno (Quadro 1).

Foi analisado o conteúdo dos seguintes documentos das empresas: Formulário de Referência 10.6 Controles Internos (B3); e das Demonstrações Financeiras Padronizadas - Pareceres e Declarações (B3); e do ofício de refazimento (CVM). Para cada dimensão de deficiência (Quadro 1), foram extraídas as ocorrências identificadas nestes relatórios, atribuindo-se o número de deficiências identificadas em cada dimensão, ou 0 (zero) caso não houvessem deficiências de controle interno. 


\begin{tabular}{ll}
\hline \multicolumn{1}{c}{ Variáveis } & \multicolumn{1}{c}{ Descrição de cada tipo de deficiência } \\
\hline Conta Específica & $\begin{array}{l}\text { Operações com regulamentação complexa; Transações não rotineiras e sistemáticas; } \\
\text { Transações internacionais da administração; Incerteza de mensuração; Mensurações } \\
\text { contábeis complexas. }\end{array}$ \\
Demonstrações Contábeis & $\begin{array}{l}\text { Instrumentos financeiros não registrados; Pessoal da área contábil; Histórico de erros } \\
\text { passados; Normas contábeis; Distorções contábeis futuras. } \\
\text { Controle compartilhado; Transações com partes relacionadas; Aquisições e reorganizações; } \\
\text { Subsidiárias }\end{array}$ \\
Vendas ou probabilidades de vendas. \\
Tecnologia & $\begin{array}{l}\text { Incompatibilidade de tecnologia e negócios; Mudança de ambiente de tecnologia; Novos } \\
\text { sistemas tecnológicos. }\end{array}$ \\
Alta Administração & $\begin{array}{l}\text { Operaços instáveis e voláteis; Continuidade dos negócios e liquidez; Mudanças atividades, } \\
\text { produtos e outros; Mudanças e/ou expansão de locais; Mudanças na alta administração. }\end{array}$ \\
Litígios & Órgãos reguladores e governamentais; Obrigações contingentes. \\
Geral & $\begin{array}{l}\text { Monitoramento geral; Revisão ou implantação de sistema de controle interno; Segregação } \\
\text { de funções; Reconciliações contábeis; Deficiências, erros e fraudes. }\end{array}$ \\
\hline
\end{tabular}

Quadro 1. Variáveis para a composição do índice de deficiência de controle interno

Fonte: Adaptado de Teixeira (2015).

Nota: A deficiência foi identificada pela análise de conteúdo dos seguintes documentos: Formulário de Referência 10.6 - Controles Internos (B3); das Demonstrações Financeiras Padronizadas - Pareceres e Declarações (B3); e do ofício de refazimento (CVM). Pela análise de conteúdo dos relatórios, cada variável foi apontada como 1 quando houve incidência de deficiência de controle interno naquela dimensão, o número de incidências quando maior que um, ou 0 quando não foi identificada incidência.

Em seguida aplicamos análise de entropia da informação. Foi gerado um índice de entropia para cada deficiência observada, e ao final multiplicamos as deficiências encontradas de cada empresa com o peso/índice de entropia de cada dimensão de deficiência. A entropia da informação, de acordo com Zeleny (1982) gera o 'peso da informação', que é uma medida de importância relativa relacionada com a quantidade de informação. Quanto mais distintos e diferenciados forem os escores de determinada variável, por exemplo, maior tende a ser o peso desta. A entropia da informação refere-se a uma análise multicritério e atribui pesos às informações, demonstrando as mais relevantes.

Esta técnica foi aplicada no estudo de Teixeira (2015), em que também se observou um índice de deficiência. Este, por sua vez, observou o peso de cada informação analisada e após pela soma destas informações, gerou um indicador. Esta técnica foi utilizada em estudos nacionais, como o de Rocha, Hein, Lavarda e Nascimento (2011) e Moura e Beuren (2011). Ao final, foi gerado um índice de deficiência de controle interno para cada empresa. O índice de deficiência é demonstrado no Quadro 2, assim como as demais variáveis do estudo. 


\begin{tabular}{|c|c|c|c|}
\hline Variável & Descrição & Origem dos Dados & Referência \\
\hline \multicolumn{4}{|c|}{ Variável Dependente } \\
\hline $\begin{array}{l}\text { Índice de Deficiência de } \\
\text { Controle interno }\end{array}$ & $\begin{array}{l}\text { Índice formado a partir das variáveis } \\
\text { de deficiências, em que após se } \\
\text { aplicar exponencial aos números, } \\
\text { aplicou-se a entropia para observar } \\
\text { o peso, multiplicando-o então com } \\
\text { o valor absoluto de deficiência, e } \\
\text { posteriormente pela soma chegou-se a } \\
\text { um único indicador. }\end{array}$ & $\begin{array}{l}\text { Dados das variáveis de } \\
\text { deficiências de controle } \\
\text { interno. }\end{array}$ & Teixeira (2015) \\
\hline \multicolumn{4}{|c|}{ Variáveis Independentes de Qualidade do Comitê de Auditoria } \\
\hline $\begin{array}{l}\text { Tamanho do comitê de } \\
\text { auditoria (número de } \\
\text { membros) }\end{array}$ & $\begin{array}{l}\text { Quantidade de membros no comitê de } \\
\text { auditoria. }\end{array}$ & $\begin{array}{l}\text { B3: Formulário de } \\
\text { Referência } 12.7- \\
\text { Composição dos Comitês. }\end{array}$ & $\begin{array}{l}\text { Krishnan (2005); } \\
\text { Goodwin-Stewart e } \\
\text { Kent (2006). }\end{array}$ \\
\hline $\begin{array}{l}\text { Comitê de Auditoria } \\
\text { com } 3 \text { ou mais } \\
\text { membros }\end{array}$ & $\begin{array}{l}\text { Variável dummy para o tamanho } \\
\text { do comitê de auditoria, em que } 1 \\
\text { representa três ou mais membros no } \\
\text { comitê e } 0 \text { inferior a três membros } \\
\text { (orientação da SEC, que se tenha no } \\
\text { mínimo três membros). }\end{array}$ & $\begin{array}{l}\text { B3: Formulário de } \\
\text { Referência } 12.7- \\
\text { Composição dos Comitês. }\end{array}$ & $\begin{array}{l}\text { Krishnan (2005); } \\
\text { Goodwin-Stewart } \\
\text { e Kent (2006), Goh } \\
\text { (2009). }\end{array}$ \\
\hline $\begin{array}{l}\text { Independência do } \\
\text { Comitê de auditoria }\end{array}$ & $\begin{array}{l}\text { Proporção de membros do comitê de } \\
\text { auditoria que são independentes. }\end{array}$ & $\begin{array}{l}\text { B3: Formulário de } \\
\text { Referência } 12.7- \\
\text { Composição dos Comitês. }\end{array}$ & $\begin{array}{l}\text { Krishnan (2005); } \\
\text { Goodwin-Stewart } \\
\text { e Kent (2006); Goh } \\
\text { (2009). }\end{array}$ \\
\hline $\begin{array}{l}\text { Expertise do Comitê de } \\
\text { auditoria }\end{array}$ & $\begin{array}{l}\text { Proporção de membros do comitê de } \\
\text { auditoria com experiência financeira: } \\
\text { contabilidade, finanças e economia. }\end{array}$ & $\begin{array}{l}\text { B3: Formulário de } \\
\text { Referência } 12.7- \\
\text { Composição dos Comitês. }\end{array}$ & $\begin{array}{c}\text { Krishnan (2005); } \\
\text { Goodwin-Stewart } \\
\text { e Kent (2006); Goh } \\
\text { (2009); Barua et al. } \\
\text { (2010). }\end{array}$ \\
\hline \multicolumn{4}{|c|}{ Variáveis Independentes de Controle } \\
\hline $\begin{array}{l}\text { Tipo de empresa de } \\
\text { auditoria }\end{array}$ & $\begin{array}{l}\text { Empresas que são auditadas por Big } \\
\text { Four }=1 \text {; empresas que não são } \\
\text { auditadas por Big Four }=0 .\end{array}$ & $\begin{array}{l}\text { B3: Formulário de } \\
\text { Referência } 2.1 / 2 \\
\text { - Identificação e } \\
\text { Remuneração Auditores } \\
\text { Independentes. }\end{array}$ & $\begin{array}{c}\text { Krishnan (2005); Ge e } \\
\text { Mcvay (2005). }\end{array}$ \\
\hline Tamanho da empresa & $\begin{array}{l}\text { Logaritmo natural do total de ativos das } \\
\text { empresas. }\end{array}$ & Economática & Krishnan (2005) \\
\hline Rentabilidade do Ativo & Fração entre lucro líquido e ativo total. & Economática & Ge e Mcvay (2005) \\
\hline
\end{tabular}

Quadro 2. Descrição das variáveis

Fonte: Dados da pesquisa.

Destaca-se que o tamanho do comitê de auditoria foi observado por duas variáveis, sendo a primeira o tamanho total do comitê de auditoria e a segunda uma variável dummy para capturar as empresas que possuíam comitê de auditoria formado por pelo menos 3 membros. Justificam-se estas duas variáveis uma vez que Krishnan (2005) constatou que o comitê apresentado por 3 membros pode apresentar maior eficiência de atuação, sendo que pela quantidade total não se consegue observar esta prerrogativa. Ainda, a independência do comitê de auditoria foi avaliada por membros no comitê que não apresentavam relações atuais e anteriores com a empresa, não sendo, por exemplo, ex-funcionários e fornecedores.

$$
\begin{gathered}
\operatorname{IDCI}_{i t}=\varphi_{0}+\varphi_{1} \operatorname{ACSIZE}_{i t}+\varphi_{2} \operatorname{ACSIZED}_{i t}+\varphi_{3} \operatorname{ACINDEP}_{i t}+\varphi_{4} \operatorname{ACEXP}_{i t} \\
+\varphi_{5} \text { BIGFOUR }_{i t}+\varphi_{6} \operatorname{LASSET}_{i t}+\varphi_{7} \operatorname{ROA}_{i t}+\varepsilon_{i t}
\end{gathered}
$$

Em que:

IDCI: índice de deficiência de controle interno;

ACSIZE: tamanho do comitê de auditoria (número de membros); 
ACSIZED: comitê de auditoria com 3 ou mais membros;

ACINDEP: independência do comitê de auditoria;

ACEXP: expertise do comitê de auditoria;

BIGFOUR: tipo de empresa de auditoria;

LASSET: tamanho da empresa;

ROA: rentabilidade do Ativo.

Apresenta-se na Tabela 1 a estatística descritiva das variáveis analisadas.

Tabela 1. Análise descritiva das variáveis do estudo

\begin{tabular}{lcccc}
\hline Variáveis & Mínimo & Máximo & Média & Desvio-Padrão \\
\hline Índice de Deficiência de Controle Interno & 0,00 & 32,81 & 0,34 & 1,68 \\
Tamanho do Comitê de Auditoria & 1 & 9 & 3,30 & 1,14 \\
Comitê com 3 ou mais membros (0/1) & 0 & 1 & 0,84 & 0,36 \\
Membros Independentes & 0 & 9 & 2,79 & 1,41 \\
Membros com Expertise & 0 & 6 & 1,64 & 1,21 \\
Auditoria por BigFour (0/1) & 0 & 1 & 0,96 & 0,19 \\
Tamanho da Empresa (total de ativos R \$ milhares) & 49 & 1.437 .485 & 70.306 & 224.098 \\
Rentabilidade do Ativo (\%) & $-179,70$ & 199,30 & 3,23 & 18,98 \\
\hline
\end{tabular}

Fonte: Dados da pesquisa.

Nota: Big Four - Deloitte; Ernst \& Young; KPMG e PricewaterhouseCooper.

De acordo com a Tabela 1, pode-se observar que o índice de deficiência de controle interno variou de 0 a 32,81 , demonstrando que algumas das empresas analisadas não apresentaram deficiências de controle interno no período analisado, enquanto outras demonstraram elevadas deficiências, como é o caso da empresa BRB Banco, que no exercício de 2014 demonstrou muitas deficiências de controle interno. De maneira geral, as empresas possuem média baixa de deficiências de controle interno $(0,34)$, o que é corroborado pelo baixo desvio padrão dos dados $(1,68)$. Observa-se uma baixa deficiência de controle interno (em média) nas empresas analisadas, o que revela poucas fragilidades na estrutura de controles internos das empresas.

Devido às empresas brasileiras demonstrarem baixo nível de deficiências de controle interno, de acordo com Ge e Mcvay (2005), infere-se que estas estão zelando por trabalhadores qualificados na contabilidade, políticas sobre reconhecimento de receitas, segregação de funções e conciliação de contas contábeis.

Os comitês implantados nessas empresas variam de 1 a 9 membros, com uma média de 3,3 membros no comitê. Ainda, contrariando a recomendação dos reguladores observa-se comitês com número par de membros também. Assim, parte delas (63 empresas - 2010 e 2011; 62 empresas - 2012; 61 empresas - 2013 e 2014 e 60 empresas - 2015); segue a recomendação da SEC, do IBGC, e da CVM. Como mostra a dummy "comitê com 3 ou mais membros", 84\% das empresas atende tal recomendação. Além disso, algumas empresas não possuem nenhum membro independente no comitê, outras estruturam o comitê com até 9 membros independentes.

A expertise em finanças, economia ou contabilidade dos membros do comitê varia de 0 a 6 membros, em média quase 2 membros. O baixo desvio padrão mostra uma menor quantidade de membros especialistas em contabilidade, finanças ou economia. Em relação ao tipo de auditoria externa, constata-se pela média $(0,96)$, que a maioria é auditada por Big Four (Deloitte; Ernst \& Young; KPMG e PricewaterhouseCooper). A amostra é formada por empresas com bilhões de reais em ativos, enquanto um dos casos possui ativos no valor de R $\$ 49$ mil em 2010 (Nutriplant Industria e Comercio S.A.).

Com o intuito de aprofundar as descrições das deficiências de controle interno, apresenta-se na Tabela 2 a análise descritiva das sete dimensões de deficiências de controle, as quais compõem o índice de deficiências de controle (já apresentado na Tabela 1). 
Tabela 2. Análise descritiva das dimensões de deficiências de controle interno

\begin{tabular}{lcccc}
\hline Variáveis & Mínimo & Máximo & Média & Desvio-Padrão \\
\hline Conta Específica & 0,00 & 32,67 & 0,13 & 1,55 \\
Demonstrações Contábeis & 0,00 & 0,81 & 0,03 & 0,12 \\
Subsidiárias & 0,00 & 0,05 & 0,00 & 0,00 \\
Tecnologia & 0,00 & 1,53 & 0,04 & 0,14 \\
Alta Administração & 0,00 & 0,05 & 0,00 & 0,00 \\
Litígios & 0,00 & 0,00 & 0,00 & 0,00 \\
Geral & 0,00 & 0,64 & 0,02 & 0,07 \\
\hline
\end{tabular}

Fonte: Dados da pesquisa.

A dimensão de maior representatividade na composição do índice de deficiências de controle interno é a de 'Deficiências com Conta Específica' (média de 0,13). Esta dimensão refere-se a problemas com Operações com regulamentação complexa; Transações não rotineiras e sistemáticas; Transações internacionais da administração; Incerteza de mensuração; Mensurações contábeis complexas (Teixeira, 2015). As deficiências em Conta Específica no período analisado (2010 a 2015) podem estar associadas ao período de adaptação das empresas brasileiras aos novos padrões trazidos pelas normas internacionais de contabilidade.

As empresas tiveram que registrar contas complexas, como Instrumentos Financeiros, e outras inexistentes até então, como Ativos Intangíveis e Ativos Biológicos. Além disso, outras alterações foram implementadas na contabilidade, como métodos de mensuração como valor justo, valor realizável líquido, custo corrente. Tais mudanças podem ter intensificado ocorrências de deficiências no período de adaptação. Observa-se, também, de acordo com a Tabela 2, que a dimensão de Litígios não sofreu qualquer menção, uma vez que de acordo com Teixeira (2015) refere-se à ação ou controvérsia judicial com órgãos reguladores e governamentais ou obrigações contingentes. Assim, infere-se que as empresas analisadas não tiveram qualquer problema com litígios no período analisado. As demais dimensões de deficiências de controle interno se comportaram de forma semelhante, demonstrando problemas nas empresas, porém não de forma elevada.

\section{DESCRIÇÃO E ANÁLISE DOS RESULTADOS}

A Tabela 3 apresenta o resumo da regressão linear múltipla, em que se utilizou das variáveis observando a proporção dos membros com o ativo logaritmizado, ou seja, as variáveis demonstradas no Quadro 1. A regressão linear múltipla foi rodada por etapas, tendo ao final do modelo somente a(s) variável(eis) que são significativas.

Observa-se com base na Tabela 3, que pela regressão linear múltipla por etapas, somente o tamanho do comitê de auditoria - com 3 ou mais membros - se manteve com influência significativa e negativa nas ocorrências de deficiências de controle interno. As demais variáveis, tais como o número total de membros no comitê de auditoria, a independência do comitê de auditoria, a expertise dos membros do comitê, auditoria por BigFour, tamanho da empresa e a rentabilidade do ativo, todas não estão associadas significativamente com a ocorrência de deficiências de controle interno, sendo excluídas do modelo.

O uso de regressão por etapas corrige o baixo grau de liberdade que comprometeria a significância da Regressão por Mínimos Quadrados Parciais $\left(\mathrm{PLS}^{3}\right)$. Nesse modelo por etapas, o comitê de auditoria com três ou mais membros $\left(\mathrm{R}^{2}\right.$ de $\left.0,011,-0,472\right)$ indica que um comitê diminuto ( 2 membros) teria maior propensão a ocorrência de deficiências de controle interno na amostra analisada ${ }^{4}$.

\footnotetext{
${ }^{3}$ PLS - Regressão por Mínimos Quadrados Parciais refere-se a uma técnica de estimação de modelo de regressão linear indicado para grandes amostras (Morellato, 2010).

${ }^{4}$ Foram analisados os pressupostos da análise multivariada como teste de normalidade, Durbin Watson e colinearidade, demonstrando atendimento a tais testes, caso o teste de normalidade não se demonstre significativo (Corrar, Paulo \& Dias Filho, 2014), o Durbin Watson em torno de 2 (Hair, Anderson, Tatham, \& Black, 2005) e a colinearidade abaixo de 10 para todas as variáveis (Corrar, Paulo \& Dias Filho, 2014).
} 
Tabela 3. Resumo da regressão linear múltipla

\begin{tabular}{lccc}
\hline Variáveis & Coef. & Sig. & VIF \\
\hline (Constante) & 0,735 & 0,000 & - \\
Comitê de auditoria com 3 ou mais membros & $-0,472$ & $0,032^{*}$ & 1,000 \\
\hline Durbin Watson & 1,987 & & \\
$\mathrm{R}^{2}$ equação: & 0,011 & \\
Sig equação: & $0,032^{*}$ & & \\
\hline \multicolumn{1}{c}{$\quad$ Variáveis excluídas do modelo pela regressão linear múltipla em etapas. } \\
\hline Variáveis & Coef. & Sig. & VIF \\
Tamanho do comitê (número de membros) & 0,002 & 0,977 & 1,478 \\
Independência do comitê de auditoria & $-0,040$ & 0,404 & 1,011 \\
Expertise do comitê de auditoria & 0,040 & 0,399 & 1,000 \\
Auditoria por BigFour & 0,034 & 0,479 & 1,000 \\
Tamanho da empresa & $-0,015$ & 0,751 & 1,007 \\
Rentabilidade do ativo & 0,000 & 0,998 & 1,017 \\
\hline Fos & & &
\end{tabular}

Fonte: Dados da pesquisa.

Nota: * Significativo a 5\%.

A regressão linear múltipla em etapas ou stepwise apresenta um modelo que possui somente variáveis com parâmetros significativos para a explicação da variável dependente. Assim, conforme os parâmetros das variáveis vão sendo testados, elas são adicionadas ou não ao modelo. A inclusão no modelo depende de a variável apresentar significância estatística e influência na variável dependente (Fávero, Belfiore, Silva \& Chan, 2009, pg. 365 e 366).

Para confirmar o efeito do mínimo de 3 membros no comitê, a Tabela 4 apresenta as diferenças de média das ocorrências de deficiências de controle interno entre grupos de comitê: formados por 3 ou mais membros (ou não), com (ou sem) independência e com (ou sem) expertise.

Tabela 4. Diferença de média de nível deficiências de controle interno entre grupos do comitê formado por 3 membros, independência e expertise dos membros.

\begin{tabular}{lcccc}
\hline \multicolumn{5}{c}{ Teste t para ocorrências de deficiência de controle interno } \\
\hline \multicolumn{1}{c}{ Grupo } & $\mathbf{n}$ & Média & Teste Levene. & Sig. \\
\hline Menos de 3 membros (0) & 69 & 0,74 & $0,00^{*}$ & \multirow{2}{*}{0,32} \\
Igual ou maior que 3 membros (1) & 370 & 0,26 & 0,23 & \multirow{2}{*}{0,73} \\
\hline Sem independência (0) & 29 & 0,23 & 0,70 \\
Com independência (1) & 410 & 0,34 & 0,45 & \\
\hline Sem expertise (0) & 76 & 0,27 & & \\
Com expertise (1) & 363 & 0,35 & & \\
\hline
\end{tabular}

Fonte: Dados da pesquisa.

Nota: Foi considerado "Com" expertise e independência os membros que apresentavam algum grau, e os "Sem" expertise e independência os que não apresentavam qualquer grau.

*A correlação é significativa no nível 0,05 (2 extremidades).

**A correlação é significativa no nível 0,01 ( 2 extremidades).

O Teste de Levene revela se o pressuposto de igualdade de variâncias foi respeitado $(p>0,05)$ ou violado $(p<0,05)$, o que sugere a significância do Teste $\mathrm{T}$ a ser analisado.

Confirma-se que o nível de deficiências de controle interno não apresentou diferença de média estatisticamente significativa entre os grupos comitê formado por 3 membros, expertise e independência (rejeitando hipóteses 1, 3 e 4). Os resultados não corroboram os achados de estudos internacionais no que se refere a expertise e independência. Estes dois fatores são relevantes em Krishnan (2005) e Zhang et al. (2007) na redução da incidência de problemas de controle interno. Nos testes apresentados para o Brasil, não observamos o efeito da expertise e da independência dos membros. O efeito observado anteriormente (Tabela 3) para comitês com no mínimo 3 membros permite aceitar a hipótese 2 . 
O comitê de auditoria é responsável por supervisionar o processo de auditoria, divulgar informações, revisar procedimentos contábeis e corrigir problemas de controle (Goh, 2009; Peleias et al.,2009). Pela NYSE, NASDAK, SEC, IBGC e demais organismos, os comitês de auditoria, para realizarem eficazmente suas atividades, devem ter no mínimo três membros, em que de acordo com o IBGC (2017) este número ímpar de membros facilita a pluralidade de argumentos. Com base nos resultados, a proposição desses reguladores ganha força, pois ao menos no Brasil no período analisado, não seria necessário um comitê com quantidade elevada de membros para mitigar as ocorrências de deficiências, mas sim no mínimo três membros. Este achado corrobora os de Krishnan (2005), em que as empresas americanas com propensão a ter comitês formados por três ou mais membros, demonstraram maior qualidade de atuação. Segundo o IBGC (2017) esta composição de três membros no comitê auxilia a diversidade de perfis e experiências, promovendo visões diferenciadas para o processo de tomada de decisão, o que auxilia o debate e reflexão. Assim, uma mínima pluralidade no comitê incentivaria comunicação e decisões de maior qualidade e segurança nos processos organizacionais.

Por fim, a Tabela 5 mostra que, maior expertise e independência são observados em comitês formados por 3 membros ou mais membros. Esse resultado tem significado relevante. Ao não atenderem as recomendações mínimas dos reguladores, as empresas também não fazem esforços em instrumentalizar os comitês com recursos (expertise) e autonomia (independência). O que faz com que tais comitês possam ser meramente cerimoniais. Outro efeito interessante, é observar que entre os comitês com 3 ou mais membros (chegam até 9 membros), a média de membros independentes não descola dos mínimos $3(3,05)$, e ainda, a média dos membros especialistas nem a 3 chega $(1,79)$.

Tabela 5. Diferença de média do nível de expertise e de independência entre comitês com menos de 3 membros vs. 3 ou mais membros.

\begin{tabular}{|c|c|c|c|c|c|}
\hline \multicolumn{6}{|c|}{ Teste $t$} \\
\hline & Grupo & $\mathbf{n}$ & Média & Teste Levene & Sig. \\
\hline \multirow{2}{*}{ Membros com Expertise } & Menos de 3 membros $(0)$ & 69 & 0,83 & \multirow{2}{*}{$0,00^{*}$} & \multirow{2}{*}{$0,00 *$} \\
\hline & Igual ou Mais de 3 membros (1) & 370 & 1,79 & & \\
\hline \multirow{2}{*}{ Membros com Independência } & Menos de 3 membros $(0)$ & 69 & 1,40 & \multirow{2}{*}{0,31} & \multirow{2}{*}{$0,00 *$} \\
\hline & Igual ou Mais de 3 membros (1) & 370 & 3,05 & & \\
\hline
\end{tabular}

Fonte: Dados da pesquisa.

Nota: *A correlação é significativa no nível 0,05 (2 extremidades).

**A correlação é significativa no nível 0,01 ( 2 extremidades).

Como apenas parte das empresas brasileiras não são listadas na SEC e, portanto, não seguem requisitos compulsórios sobre o comitê de auditoria, a análise das empresas listadas apenas no Brasil observa a adoção do comitê em um caráter voluntário. Salvo empresas de setores/segmentos regulados por instruções específicas, como é o caso de empresas financeiras e estatais, que participam do Novo Mercado da B3. Para estas empresas é recomendado adotarem o comitê de auditoria.

Baseados nestes resultados, sugere-se a atenção dos órgãos de regulação, auditoria e governança corporativa, para a composição dos comitês justamente na faixa dos 3 membros, quanto à sua composição em termos de independência e expertise. A baixa expertise empregada (menor que 3 dos mínimos recomendados) mostra que os comitês atendem o mínimo da regulação, mas não agregando membros com expertise. A menor propensão a deficiências de controle pode advir da existência e composição do comitê. Além disso, usuários externos às empresas podem aproximar e antecipar o nível de eficiência de controle interno destas, sabendo que existe forte relação entre comitês diminutos e deficiências de controle.

\section{CONCLUSÕES}

A presente pesquisa analisou a relação entre as características do comitê de auditoria e as deficiências do controle interno em empresas brasileiras. No total, foram considerados 80 comitês, e 439 observações entre o período de 2010 a 2015, em uma amostra não balanceada. Foi construído um índice de deficiências de controle interno, como em Teixeira (2015), coletando incidência de deficiências em diversas dimensões por meio de análise de conteúdo de relatórios das empresas. Por fim, usou-se entropia da informação para ponderar a quantidade de deficiências reportadas pelas empresas. 
Os resultados mostram que entre as características do comitê de auditoria (tamanho, independência e expertise), a formação do comitê de auditoria de no mínimo três membros está associada com a diminuição das deficiências de controle interno. Ainda, as deficiências de controle interno nas empresas analisadas não variam com independência ou expertise em seu comitê de auditoria, ou com o porte ou rentabilidade do ativo das empresas.

Observou-se que esta indicação de três membros no mínimo no comitê (por NYSE, NASDAK, SEC e IBGC), pode ser um indicativo para as empresas brasileiras que optaram por adotar o comitê de auditoria para aprimorar o controle interno, uma vez que facilita a pluralidade de perfis, experiências e argumentos, o que corrobora para a qualidade do processo de tomada de decisão. Estes resultados podem ser de interesse de usuários das informações contábeis, pois uma maior atuação do comitê de auditoria estaria associada à confiabilidade da informação contábil. O estudo traz algumas limitações. Primeiro, considerou apenas as empresas brasileiras que possuem comitê de auditoria, em 6 exercícios fiscais. Por fim, não foram consideradas empresas que possuem comitê fiscal, que também exercem função de governança corporativa, porém não diretamente associada ao controle interno.

\section{REFERÊNCIAS}

Abbott, L. J., Parker, S. \& Peters, G. F. (2004). Audit committee characteristics and restatements. Auditing: A Journal of Practice \& Theory, 23(1), 69-87. DOI: https://doi.org/10.2308/aud.2004.23.1.69

Barua, A., Rama, D. V. \& Sharma, V. (2010). Audit committee characteristics and investment in internal auditing. Journal of Accounting and Public Policy, 29(5), 503-513. DOI: https://doi.org/10.1016/j.jaccpubpol.2010.09.001

Bedard, J. C. \& Graham, L. (2011). Detection and severity classifications of Sarbanes-Oxley Section 404 internal control deficiencies. The Accounting Review, 86(3), 825-855. DOI: https://doi.org/10.2308/accr.00000036

BM\&FBOVESPA (2018). B3: Uma das principais empresas de infraestrutura de mercado financeiro do mundo. Disponível em <http://www.bmfbovespa.com.br/pt_br/institucional/sobre-a-bm-fbovespa/quem-somos/>. Acesso em 22 de junho de 2018.

Carcello, J. V. \& Neal, T. L. (2003). Audit committee characteristics and auditor dismissals following "new" going-concern reports. The Accounting Review, 78(1), 95-117. DOI: https://doi.org/10.2308/accr.2003.78.1.95

Corrar, L. J; Paulo, E. \& Dias Filho, J. M. (2014). Análise Multivariada: para os cursos de administração, ciências contábeis e economia, 1 ed., 5 reimp. São Paulo: Atlas.

Doyle, J., Ge, W. \& Mcvay, S. (2007). Determinants of weaknesses in internal control over financial reporting. Journal of accounting and Economics, 44(1), 193-223. DOI: https://doi.org/10.1016/j.jacceco.2006.10.003

Fávero, L. P.; Belfiore, P.; Silva, F. D. \& Chan, B. L. (2009). Análise de dados. Modelagem multivariada para tomada de decisões. Rio de Janeiro: Campus.

Ge, W. \& Mcvay, S. (2005). The disclosure of material weaknesses in internal control after the Sarbanes-Oxley Act. Accounting Horizons, 19(3), 137-158. DOI: https://doi.org/10.2308/acch.2005.19.3.137

Goh, B. W. (2009). Audit committees, boards of directors, and remediation of material weaknesses in internal control*. Contemporary Accounting Research, 26(2), 549-579. DOI: https://doi.org/10.1506/car.26.2.9

Goodwin-Stewart, J. \& Kent, P. (2006). Relation between external audit fees, audit committee characteristics and internal audit. Accounting \& Finance, 46(3), 387-404. DOI: https://doi.org/10.1111/j.1467-629X.2006.00174.X

Hair, J. F., Jr, Anderson, R. E., Tatham, R. L \& Black, W. C. (2005). Análise multivariada de dados. 5. ed. São Paulo: Bookman.

Hogan, C. E. \& Wilkins, M. S. (2008). Evidence on the Audit Risk Model: Do Auditors Increase Audit Fees in the Presence of Internal Control Deficiencies?*. Contemporary Accounting Research, 25(1), 219-242. DOI: https://doi.org/10.1506/car.25.1.9

IBGC - Instituto Brasileiro De Governança Corporativa (2017). Orientações sobre comitês de auditoria: melhores práticas no assessoramento ao conselho de administração. São Paulo: IBGC/IBRACON, 2017. Disponível em: <http://www.ibgc.org.br/userfiles/files/Publicacoes/IBGC_Orienta/Publicacao-IBGCOrienta-ComiteAuditoria-2017.pdf $>$. Acesso em 23 de junho de 2018. 
Inaam, Z. \& Khamoussi, H. (2016). Audit committee effectiveness, audit quality and earnings management: a meta-analysis. International Journal of Law and Management, 58(2). DOI: https://doi.org/10.1108/IJLMA-01-2015-0006

Kim, Y. \& Park, M. S. (2009). Market uncertainty and disclosure of internal control deficiencies under the Sarbanes-Oxley Act. Journal of Accounting and Public Policy, 28(5), 419-445. DOI: https://doi.org/10.1016/j. jaccpubpol.2009.07.004

Klein, A. (2002). Audit committee, board of director characteristics, and earnings management. Journal of accounting and economics, 33 (3), 375-400. DOI: https://doi.org/10.1016/S0165-4101(02)00059-9

Krishnan, J. (2005). Audit committee quality and internal control: An empirical analysis. The accounting review, 80(2), 649-675. DOI: https://doi.org/10.2308/accr.2005.80.2.649

Lin, S., Pizzini, M., Vargus, M. \& Bardhan, I. R. (2011). The role of the internal audit function in the disclosure of material weaknesses. The Accounting Review, 86(1), 287-323. DOI: https://doi.org/10.2308/accr.00000016

Morellato, S. A. (2010) Modelos de regressão PLS com erros heteroscedásticos. (Dissertação) Departamento de Estatística, Universidade Federal de São Paulo, São Paulo, Brasil.

Moura, G. D., \& Beuren, I. M. (2011). Conselho de Administração das Empresas de Governança Corporativa Listadas na BM\&Fbovespa: análise à luz da entropia da informação da atuação independente. Revista de Ciências da Administração, 13(29). DOI: 10.5007/2175-8077.2011v13n29p11

NBC TA 265 - Comunicação de Deficiências de Controle Interno.

NBC TA 315 - Identificação e Avaliação dos Riscos de Distorção Relevante por meio do Entendimento da Entidade e do seu Ambiente.

Peleias, I. R., Segreti, J. B. \& Costa, C. A. (2009). Comitê de auditoria ou órgãos equivalentes no contexto da Lei Sarbanes-Oxley: estudo da percepção dos gestores de empresas brasileiras emitentes de American Depositary Receipts-ADRs. Contabilidade Vista \& Revista, 20(1), 41-65.

Rocha, I., Hein, N., Lavarda, C. E. F., \& Do Nascimento, S. (2011). A presença da entropia da informação no controle orçamentário em ambiente inovador. RAI Revista de Administração e Inovação, 8(2), 82-105. DOI: http://dx.doi.org/10.5773/rai.v8i2.566

SEC - Securities And Exchange Commission (2003). NASD and NYSE Rulemaking: Relating to Corporate Governance. Disponível em: https://www.sec.gov/rules/sro/34-48745.htm. Acesso em 12 de julho de 2018.

Silva, K. L., Oliveira, M. C., Mendes, M. M. \& Araújo, O. C. (2009). A Implementação dos Controles Internos e do Comitê de Auditoria Segundo a Lei SOX: o Caso Petrobras. Contabilidade Vista \& Revista, 20(3), 39-63.

Stefaniak, C. M., Houston, R. W. \& Cornell, R. M. (2012). The effects of employer and client identification on internal and external auditors' evaluations of internal control deficiencies. Auditing: A Journal of Practice \& Theory, 31(1), 39-56. DOI: https://doi.org/10.2308/ajpt-10179

Teixeira, S. A. (2015). Efeito Moderador das deficiências do controle interno na relação entre seus determinantes e consequentes. 348 f. (Tese de Doutorado). Programa de Pós-Graduação em Ciências Contábeis, Doutorado em Ciências Contábeis e Administração, Universidade Regional de Blumenau, Santa Catarina, Brasil.

Zeleny, M. (1982). Multiple criteria decision making. New York: McGraw-Hill Book Company.

Zhang, Y., Zhou, J. \& Zhou, N. (2007). Audit committee quality, auditor independence, and internal control weaknesses. Journal of accounting and public policy, 26(3), 300-327. DOI: https://doi.org/10.1016/j.jaccpubpol.2007.03.001

\section{Como citar este artigo}

Silva, A., Cunha, P. R. \& Teixeira, S. A. (2018). Recomendações aos comitês de auditoria em empresas brasileiras. Revista de Contabilidade e Organizações, 12:e138529. DOI: http://dx.doi.org/10.11606/ issn.1982-6486.rco.2018.138529 